\title{
LYMFASIM, a simulation model for predicting the impact of lymphatic filariasis control: quantification for African villages
}

\author{
WILMA A. STOLK*, SAKE J. DE VLAS, GERARD J. J. M. BORSBOOM \\ and J. DIK F. HABBEMA
}

Department of Public Health, Erasmus MC, University Medical Center Rotterdam, P.O.Box 2040, 3000 CA Rotterdam, The Netherlands

(Received 13 March 2008; revised 31 Fuly 2008; accepted 7 August 2008)

\author{
SUMMARY
}

LYMFASIM is a simulation model for lymphatic filariasis transmission and control. We quantified its parameters to simulate Wuchereria bancrofti transmission by Anopheles mosquitoes in African villages, using a wide variety of reported data. The developed model captures the general epidemiological patterns, but also the differences between communities. It was calibrated to represent the relationship between mosquito biting rate and the prevalence of microfilariae (mf) in the human population, the age-pattern in $\mathrm{mf}$ prevalence, and the relation between $\mathrm{mf}$ prevalence and geometric mean $\mathrm{mf}$ intensity. Explorative simulations suggest that the impact of mass treatment depends strongly on the mosquito biting rate and on the assumed coverage, compliance and efficacy. Our sensitivity analysis showed that some biological parameters strongly influence the predicted equilibrium pre-treatment mf prevalence (e.g. the lifespan of adult worms and $\mathrm{mf}$ ). Other parameters primarily affect the post-treatment trends (e.g. severity of density dependence in the mosquito uptake of infection from the human blood, between-person variability in exposure to mosquito bites). The longitudinal data, which are being collected for evaluation of ongoing elimination programmes, can help to further validate the model. The model can help to assess when ongoing elimination activities in African populations can be stopped and to design surveillance schemes. It can be a valuable tool for decision making in the Global Programme to Eliminate Lymphatic Filariasis.

Key words: lymphatic filariasis, Wuchereria bancrofti, Anopheles, transmission dynamics, simulation model, Africa, mass treatment, elimination.

\section{INTRODUCTION}

Lymphatic filariasis (LF) is a tropical disease, which is caused by lymphatic-dwelling filarial parasites and is transmitted by mosquitoes that engorge the immature larval forms (microfilariae, $\mathrm{mf}$ ) with a blood meal. Wuchereria bancrofti is responsible for $>90 \%$ of all infections worldwide, while Brugia malayi and Brugia timori account for the remaining infections. Chronic infection with LF can cause gross swelling of extremities or the scrotum (lymphoedema, hydrocoele). The Global Programme to Eliminate Lymphatic Filariasis aims to eliminate this debilitating disease as a public health problem (World Health Organization, 2006). Yearly mass treatment is provided to reduce the $\mathrm{mf}$ reservoir to such low levels that transmission becomes insignificant and is eventually interrupted. However, questions are being raised about the feasibility of elimination (Gyapong

* Corresponding author: Dr. W. A. Stolk, PhD, Department of Public Health, Erasmus MC, University Medical Center Rotterdam, P.O.Box 2040, 3000 CA Rotterdam, The Netherlands. Phone: +31 107038460 , Fax: +31010 7038474, e-mail:w.stolk@erasmusmc.nl and Twum-Danso, 2006). In fact, we do not know how long mass drug administration should be continued, how that depends on local conditions, or how we can establish that transmission interruption is achieved. Models can help to answer these questions and further development of mathematical models has been identified as a priority in LF research (Dadzie, Basáñez and Richards, 2004).

Several models have been developed for the simulation of LF transmission and control (Chan et al. 1998; Plaisier et al. 1998; Rochet, 1990). All three models were quantified for $W$. bancrofti infection and validated using the detailed longitudinal epidemiological and entomological data that were available from urban Pondicherry in India (Chan et al. 1998; Subramanian et al. 2004). Thus far, the role of these models in decision support in control programmes is still modest. The main reason is that model predictions made for Pondicherry are not necessarily generalisable to other areas. If adjustments are made for differences in exposure to mosquito bites, then the model should be valid for other Indian areas, assuming that the basic biological assumptions are correct. However, the model cannot be used in regions with other vector or parasite species, because of known differences in the 


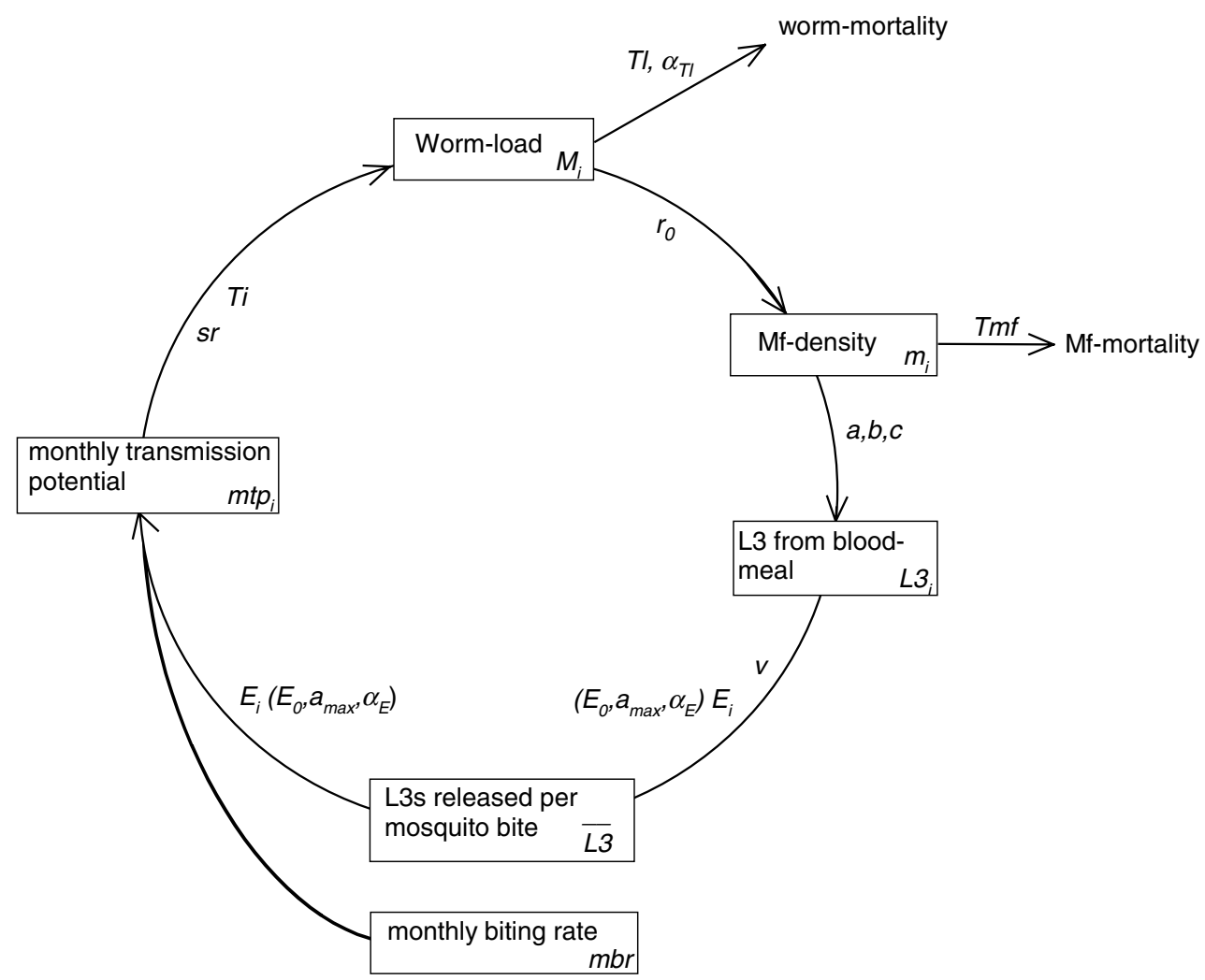

Fig. 1. Schematic representation of LYMFASIM, showing the processes that determine parasite transmission and the worm load in humans. The diagram shows the time-dependent model variables (boxes) and their interrelation (arrows). The associated model parameters are given along the arrows. Subscript ' $i$ ' indicates variables and parameters that vary between individuals. Processes related to optional immune responses are not included in the figure. See Appendix 1 for further explanation.

transmission dynamics (Southgate, 1992; Snow and Michael, 2002; Snow et al. 2006). To support decision making in the elimination programmes worldwide, we need vector-parasite specific, validated model variants (Dadzie et al. 2004; Stolk, de Vlas and Habbema, 2006).

The LYMFASIM program provides a flexible framework for simulating LF transmission and control (Plaisier et al. 1998). It can easily be adjusted to reflect the transmission dynamics in specific areas or to test models with alternative assumptions about the mechanisms involved in transmission. In this paper, we show how the parameters of LYMFASIM can be quantified to simulate $W$. bancrofti transmission by Anopheles mosquitoes in African communities. Emphasis is on capturing the general epidemiological patterns, but also the differences between communities. Therefore, the model is tested against cross-sectional data from many different locations, including data on the relationship between mosquito biting rates and local endemicity levels. A detailed sensitivity analysis is performed to explore how changes in parameter values influence the predicted long-term impact of mass treatment. For another example of the applicability of such an approach to modelling the transmission and control of another vector-borne infection, we refer to Smith et al. (2008, in this special issue).

\section{MATERIALS AND METHODS}

\section{The LYMFASIM simulation model}

LYMFASIM simulates the spread of $W$. bancrofti in a human community and the impact of control measures. A formal mathematical description of the model is provided elsewhere (Plaisier et al. 1998). Appendix 1 summarizes its main features and Table 1 explains the symbols that are used in the following section. A schematic representation of the variables and processes involved in transmission is provided in Fig. 1.

\section{Quantification of the model for Africa}

In a previous study, all parameters of LYMFASIM were quantified for simulating the transmission of Wuchereria bancrofti by Culex quinquefasciatus mosquitoes in Pondicherry, India (Subramanian et al. 2004). We now set out to quantify the parameters for Africa. However, we changed the assumptions about immunity. The Pondicherry model included strong acquired immunity to explain that infection levels declined in elderly individuals (Subramanian et al. 2004). Epidemiological data from Africa provide no indication of patterns consistent with such acquired immunity (Stolk et al. 2004), and we discard it in the current model. 
Some model parameters can take the same value in the models for Pondicherry and Africa because their value is independent of the area under study and vector species. This presumably applies to parameters that relate to infection in the human host, including several parameters of the parasite life cycle $\left(T l, T i, T m f, r_{0}, \alpha_{T l}\right)$ and the aggregation parameter $(k)$ of the negative binomial distribution that quantifies the stochastic variability in mf counts in human blood samples. For the age-pattern in human exposure to mosquitoes, we assume that the exposure is zero in newborns $\left(E_{0}\right)$ and that the maximum exposure is achieved in adults at age 20 .

The uptake curve, which describes the relation between the mf density in human blood and the number of L 3 developing in mosquitoes after a blood meal, depends on the vector species involved in transmission. The uptake curve was quantified for Anopheles by analyzing published data from feeding experiments (see Appendix 2). The estimated curve shows 'facilitation', which means that the number of L3 developing in mosquitoes from a blood meal increases initially at a rate higher than that expected from a linearly proportional relationship with the $\mathrm{mf}$ density in the human blood. Only at higher $\mathrm{mf}$ densities, limiting mechanisms seem to operate so that saturation occurs ('limitation').

The demographic parameters vary considerably between India and Africa, but within Africa they also vary between locations. For the current study, we take the overall population in Sub Saharan Africa as reference. We used the Revised Global Burden of Disease 2002 estimates of numbers of deaths by age and sex in the WHO 'AFRO Region' as a whole to calculate average age-specific death rates. (Data can be downloaded in spreadsheet format from the World Health Organization website, www.who.int.) These death rates were then used to construct a life table for the African region. Age-specific fertility rates for Sub-Sahara Africa were available from the US Census Bureau (2004). Exact quantification of fertility and mortality rates does not necessarily result in realistic age-structure of the simulated population, if historic trends in the rates over time and migration effects are ignored. To verify whether the age-structure of the simulate population is sufficiently adequate, we compared it with published population pyramids for sub Saharan Africa (US Census Bureau, 2004).

The average monthly biting rate $(m b r)$ was the only parameter which we assumed to be varying between communities. We adjusted this parameter to simulate different endemicity levels. From published entomological studies, which measured the annual biting rate based on repeated all-night human landing catches, we estimated the range of possible values for the average $m b r$.

Two parameters were unknown and were estimated by fitting the model to data: (1) the success ratio $s r$, i.e. the probability that an infectious L3 larva, which is released during a mosquito blood meal, survives to develop into a mature adult worm; and (2) the variability in exposure to mosquito bites (defined by shape parameter $\alpha_{E}$ of the gamma distribution). The Pondicherry-derived estimates for these parameters cannot be used because they were conditional on the inclusion of acquired immunity. In fact, a third parameter is also unknown, namely the fraction of the L3 larvae resulting from a single blood meal that is eventually released by a mosquito $(v)$. However, $v$ and $s r$ are linear multiplication factors in the same sequence of calculations and cannot be estimated independently; therefore, we fixed $v$ at a biologically plausible value of $0 \cdot 1$ and only estimated the success ratio $s r$.

\section{Fitting procedure}

We did a grid search to determine the values for the two unknown parameters that resulted in the best fit of model outcomes to data, based on visual assessment. For each pair of values for the success ratio $(s r)$ and variability in exposure $\left(\alpha_{E}\right)$, we performed a series of 3100 simulation runs. Each series consisted of 100 repeated runs for 31 different $m b r$ values, ranging from 100 to 4000 bites per person per month $(\mathrm{mbr} 100,150, \ldots, 1000$; larger increments thereafter). All runs started with a 125-year 'burn-in' period to achieve a dynamic equilibrium endemicity level and a population with stable age-sex composition and an average size of about 6000 individuals. The results of each series of runs were summarized, to allow comparison with field data.

A well-fitting model had to satisfy the following three criteria. Firstly, the simulated relationship between $m b r$ and overall $\mathrm{mf}$ prevalence should match that observed in various localities of the African region. Observed data about the relationship between overall $\mathrm{mf}$ prevalence and average monthly biting rate were obtained from a PubMed literature search. We only included studies from locations in SubSaharan Africa where Anopheles mosquitoes act as the main vectors. Studies were excluded if the largest part of sampled mosquitoes were $C$. quinquefasciatus and not Anopheles. Selected studies used repeated allnight human landing catches to measure the biting rate. Because only few studies were available, we did not impose selection criteria on the type of test used for diagnosing microfilaraemia in this part of the fitting procedure.

The simulation results are represented by a single curve, which provides the expected average $\mathrm{mf}$ prevalence by $m b r$. We anticipated that deviations of observations from the theoretical curve would be large, because the field data are subject to many sources of variation that are not considered in the model. To assess whether these deviations are still acceptable (i.e. whether they represent natural 
variation or indicate deviations that would cast doubts on the model), we calculated the range of possible model outcomes that would be obtained if model results were subjected to the same sources of variation as those in the field data. Unpublished field data from Ghana suggest that the annual biting rate (or similarly, the annual mean $m b r$ ) can vary over time by a factor of approximately 3 around its average value (Dr D. Boakye, personal communication). This reflects measurement error and sampling variation, but also true fluctuations in the vector density and biting rate over time. We assumed that the variation around the $\log (m b r)$ is described by a uniform distribution, which ranges from $\log (\mathrm{mbr} / 3)$ to $\log (3 \mathrm{mbr})$. We also considered sampling variation in measuring human mf prevalence levels, assuming that the variability is described by a normal distribution, with the average simulated $\mathrm{mf}$ prevalence as expected value $p$ and standard deviation $\sqrt{p(1-p) / N}$, i.e. using the normal approximation to the binomial distribution (valid if $p N$ or $(1-p) N>5$ or 10 (Armitage and Berry, 1994)). For $N$, we took a value of 100 , which reflected the median population size in the observations. For each simulated situation, we assessed the range of possible outcomes for the $m b r$ and $\mathrm{mf}$ prevalence relationship, by randomly sampling from the probability distributions that describe the variability. We then determined the $2 \cdot 5$ th to $97 \cdot 5$ th percentile range for the possible outcomes.

Secondly, the predicted quantitative relation between $\mathrm{mf}$ prevalence and geometric mean $\mathrm{mf}$ intensity (GMI) levels in mf-positives should match with observations. To prevent bias by variation in the age-composition of the sampled populations, we plotted observed and simulated values by age group. Simulation results are summarized in a curve that shows average GMI by $\mathrm{mf}$ prevalence. Observed data were obtained by searching PubMed for published studies presenting age-specific data on $\mathrm{mf}$ prevalence and geometric mean mf intensity for SubSaharan African communities. The search strategy with inclusion and exclusion criteria is documented elsewhere (Stolk et al. 2004). We only considered studies that used $\mathrm{mf}$ counts in $20 \mu \mathrm{L}$ night blood smears for the mf counts, because this is the default diagnostic test embedded in LYMFASIM.

Thirdly, simulated age-patterns of $\mathrm{mf}$ prevalence should mimic the observed patterns for different endemicity levels. For testing this, we used the same data as in the assessment of the relation between $\mathrm{mf}$ prevalence and GMI, and additional studies that only presented prevalence data. Observed data were grouped according to the overall $\mathrm{mf}$ prevalence level in the community (very low, low, intermediate or high $\mathrm{mf}$ prevalence). These observations were then compared with model-predicted age-patterns in $\mathrm{mf}$ prevalence for different $m b r$ values. Biting rates were not known in the field studies; we selected values for the $m b r$ that matched with the average overall prevalence in each of the four groups. Unsuccessful runs, which by chance died out during the burn-in phase of the simulation while a stable endemic situation was expected, were not included in the current analysis. This only occurred with low $m b r$ values.

\section{Simulations based on nominal parameter values and sensitivity analysis}

To investigate the behaviour of the model, we simulated the impact of a 6-year mass treatment programme on trends in $\mathrm{mf}$ prevalence. In our default simulations, we performed four series of 500 repeated runs, using the parameter values that were derived in the current study. The four series only differed with respect to the assumed biting rate $(m b r=500,750,1000$ or 2000$)$. Assumptions about treatment are given in Table 3 . In view of the large uncertainty about the effects of drug treatment on adult worms, we do not claim to simulate a specific treatment regimen. Yet, the chosen parameters are in the range of 'guesstimates' for existing antifilarial drugs and drug combinations (see Stolk et al. (2005) for a discussion of available evidence). Each simulation run starts with a burn-in period and the resulting endemic equilibrium situation is taken as pre-treatment, time 0 , situation. At time 0 , the first treatment is provided and subsequent treatments are given with one-year intervals. The population is followed for 20 years after the start of treatment, via yearly epidemiological surveys. In years $0,1,2,3,4$, and 5 , the epidemiological surveys just precede the treatment. The results per series of runs were summarized by calculating the average $\mathrm{mf}$ prevalence at each survey, together with the 5 th to 95 th percentile range.

In a univariate sensitivity analysis, we assessed how the projected trends changed under other model parameter assumptions. With the $\mathrm{mbr}$ fixed at 750 bites per person per month, we performed new series of 500 repeated runs each. In each series, one of the model assumptions was assigned a different value from that in the default parameterisation; all other parameters kept their nominal value. Alternative values were usually chosen by multiplying the nominal value by $2 / 3$ or $3 / 2$ (or, if the nominal value of a proportion $p$ was $>50 \%$, by multiplying $(100-p)$ by these factors). For nominal proportions of $0 \%$ or $100 \%$ we chose alternative values that were still considered realistic: we used 0.40 as alternative value for relative exposure at birth $E_{0}(0$ in the default model) and $85 \%$ as alternative value for the fraction mf killed per treatment ( $100 \%$ in the default model). Other parameters were treated in a more qualitative manner. The demographic parameters were changed as a group, to simulate a younger population with somewhat higher fertility rates and higher mortality rates in adults (representing the lowest income 
countries in sub-Saharan Africa). The uptake curve was replaced by other curves with weaker or stronger density dependence, corresponding to the confidence interval around the density-dependence parameter of the nominal equation (see Appendix 2). As alternative for the semi-systematic compliance pattern described above, we considered completely random or completely systematic compliance patterns. Lastly, as alternative for random variability in the fraction of worms killed by treatment, we considered a situation where treatment effects vary between but not within individuals. i.e. any variation in treatment effects is related to individual characteristics and some individuals always have a good response to treatment, while others always respond poorly.

\section{RESULTS}

\section{Quantification of the model for Africa}

The life table and fertility rates are shown in Fig. 2A and $\mathrm{B}$ (solid lines). With these parameters, the pyramidal-shaped structure of the African population is reasonably well approximated (Fig. 2C, grey bars).

Table 1 gives the values of other LYMFASIM parameters. The estimated value for parameter $\alpha_{E}$ was $0 \cdot 26$, indicating that the probability distribution of exposure levels to mosquito bites is very skewed. The estimated value for the parameter $s r$ was $0 \cdot 00088$.

With the estimated parameter values, LYMFASIM predictions fitted well to the epidemiological data from the African region (Fig. 3). Data about the relationship between the average $m b r$ and overall $\mathrm{mf}$ prevalence were available from 11 locations in 4 countries (Table 2). As Fig. 3A illustrates, the models could simulate the entire range of observed $\mathrm{mf}$ prevalence levels, with values up to $40 \%$, by varying the monthly biting rate parameter within a realistic range. The grey-shaded area in Fig. 3A indicates that most observations are within the range of possible model outcomes if model projections were subjected to the same sources of variation as the field data (see Materials and Methods section above for explanation). Fig. 3B shows that the model-predicted relation between $\mathrm{mf}$ prevalence and geometric mean $\mathrm{mf}$ intensity in the positives reflects the general pattern in the data from 9 locations in 4 studies (Brengues, 1975; Gyapong et al. 1993, 1998; Boakye et al. 2004). The biting rate does not influence this relationship. Fig. 3C shows that the predicted age-prevalence pattern captures the main trend in locations with very low, low, intermediate or high overall $\mathrm{mf}$ prevalence. Data came from the 4 studies cited above, plus 7 other studies (McGregor, Hawking and Smith, 1952; McFadzean, 1954; Brengues, Subra and Bouchite, 1969; Juminer, Diallo and Diagne, 1971; Ripert et al. 1982; Akogun, 1991; Anosike et al. 2005). The mf prevalence increases with host age until a stable level
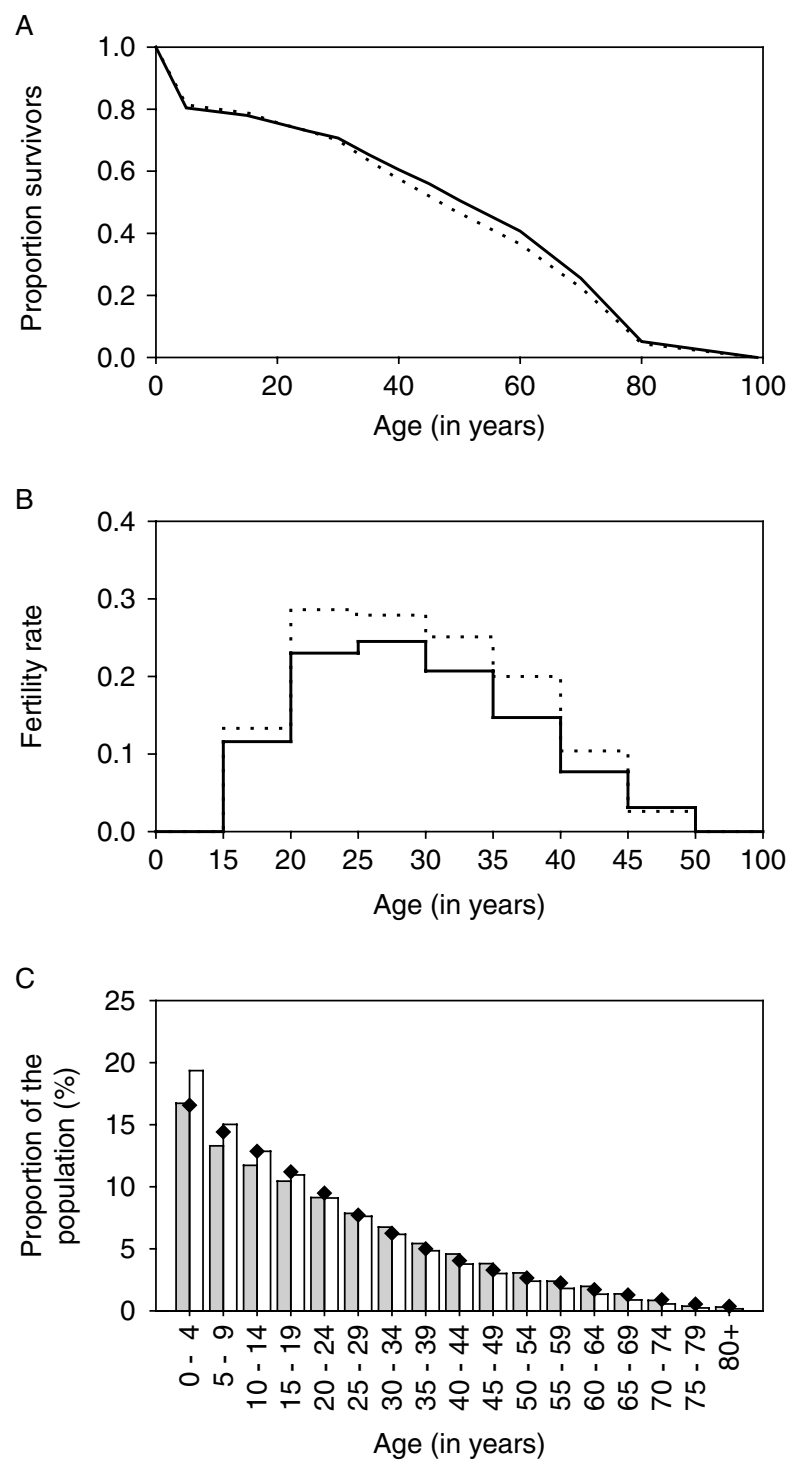

Fig. 2. Quantification of demographic parameters in LYMFASIM for modelling an African population.

A: Survival curve, showing the survival probability as a function of age. B: Age-specific fertility rates, expressed as the mean number of births per female per year.

$\mathrm{C}$ : Age-structure of the population that is simulated with the specified survival curve and fertility rates. The solid lines in $\mathrm{A}$ and $\mathrm{B}$ and the grey bars in $\mathrm{C}$ correspond to the default assumptions. The dotted lines and white bars give the alternative assumption which was used in the sensitivity analysis of simulating a younger population (with higher fertility and higher adult mortality rates).

Black diamonds show published estimates of the population pyramid for the sub Saharan Africa population in 2002 (US Census Bureau, 2004).

is reached in adults. The biting rate only influences the average $\mathrm{mf}$ prevalence level and not the shape of the age-prevalence pattern.

\section{Default simulations and sensitivity analysis}

Fig. 4 shows the results of our simulations using the nominal parameter values for areas with varying 
Table 1. LYMFASIM parameters with their nominal values for simulating transmission of lymphatic filariasis by Anopheles mosquitoes in African communities

\begin{tabular}{|c|c|c|c|}
\hline \multicolumn{2}{|c|}{ Parameter symbol and description } & \multirow{2}{*}{$\begin{array}{l}\begin{array}{l}\text { Nominal } \\
\text { value }\end{array} \\
100-4000\end{array}$} & \multirow{2}{*}{$\begin{array}{l}\text { Source } \\
\text { This paper }\end{array}$} \\
\hline$m b r$ & $\begin{array}{l}\text { Monthly biting rate, i.e. average number of mosquito bites per } \\
\text { adult person per month (range of possible values) }\end{array}$ & & \\
\hline$E_{0}$ & Relative exposure at birth (fraction of average exposure in adults) & 0 & Expert opinion \\
\hline$a_{\max }$ & Age at which exposure to mosquitoes reaches its maximum level & $20 \cdot 0$ & (Subramanian et al. 2004) \\
\hline$\alpha_{E}$ & $\begin{array}{l}\text { Shape-parameter for the gamma-distribution describing variability } \\
\text { in exposure to mosquito bites between individuals }\end{array}$ & $0 \cdot 26$ & This paper \\
\hline$a$ & Parameters of the mathematical function describing the uptake & $1 \cdot 666$ & This paper \\
\hline$b$ & of infection by Anopheles mosquitoes (the 'uptake curve’)* & $0 \cdot 027$ & (Appendix 2) \\
\hline$c$ & & $1 \cdot 514$ & \\
\hline$v$ & $\begin{array}{l}\text { Fraction of the L } 3 \text { larvae, resulting from a single blood meal, } \\
\text { that is released by a mosquito }\end{array}$ & $0 \cdot 1$ & Expert opinion \\
\hline$s r$ & $\begin{array}{l}\text { Success ratio, i.e. the probability that an infectious L } 3 \text { larva, which } \\
\text { is released during a mosquito blood meal, survives to develop } \\
\text { into a mature adult worm (fraction) }\end{array}$ & $0 \cdot 00088$ & This paper \\
\hline$T i$ & $\begin{array}{l}\text { Duration of the immature stage of the parasite in the human } \\
\text { host (months) }\end{array}$ & $8 \cdot 0$ & $\begin{array}{l}\text { (World Health } \\
\text { Organization, 1992) }\end{array}$ \\
\hline$T l$ & Average lifespan of adult parasites (years) & $10 \cdot 0$ & (Subramanian et al. 2004) \\
\hline$\alpha_{T l}$ & $\begin{array}{l}\text { Shape parameter of the Weibull distribution that describes the } \\
\text { between-worm variability in the worm lifespan }(\text { mean }=1)\end{array}$ & $2 \cdot 0$ & Expert opinion \\
\hline$r_{0}$ & $\begin{array}{l}\text { No. of mf produced per female parasite (per month per } 20 \mu \mathrm{L} \text { of } \\
\text { peripheral blood) in the presence of at least } 1 \text { male worm }\end{array}$ & $0 \cdot 58$ & (Subramanian et al. 2004) \\
\hline Tmf & Mean lifespan of microfilaria (months) & $10 \cdot 0$ & (Plaisier et al. 1999) \\
\hline$k$ & $\begin{array}{l}\text { Aggregation parameter of the negative binomial distribution } \\
\text { describing the variability in mf counts in } 20 \mu \mathrm{L} \text { blood smears } \\
\text { for an individual }\end{array}$ & $0 \cdot 33$ & (Subramanian et al. 2004) \\
\hline
\end{tabular}

* $L 3=a\left(1-\exp \left(-(b M)^{c}\right)\right.$. See Appendix 2 for further explanation.

average $m b r$, with the treatment assumptions of Table 3. Mass treatment led to elimination in areas with low average biting rates $(m b r=500)$, but to rapid recrudescence in areas with high biting rates $(\mathrm{mbr}=1000$ or 2000$)$. In areas with a biting rate of 750 , the intervention reduced $\mathrm{mf}$ prevalence to low levels, but there was a tendency for slow recrudescence. (The grey area in Fig. 4 does not have the same interpretation as that of Fig. 3A. The range of possible outcomes in Fig. 4 is much narrower, because model outcomes are conditional on the assumed constant $m b r$ value and because they ignore the non-simulated variability in $\mathrm{mf}$ prevalence measurement resulting from random sampling of the human population.)

Fig. 5 shows the results of the sensitivity analysis for a location with $m b r=750$. Four of the seven parasite biology parameters had a strong influence on the predicted $\mathrm{mf}$ prevalence levels before and after treatment, namely, the average worm lifespan, the rate of $\mathrm{mf}$ production per female worm, the average $\mathrm{mf}$ lifespan, and the success ratio of L3 larvae becoming established worms. While the strength and direction of density dependence in the uptake of infection by the mosquito barely influenced the pre-treatment $\mathrm{mf}$ prevalence, they had a very strong impact on the long-term impact of mass treatment and elimination prospects. Of the exposure-related parameters, the variability in exposure was most influential. Increased variability reduced the pretreatment $\mathrm{mf}$ prevalence, but also led to faster recrudescence of infection after cessation of treatment. Higher values for the exposure of newborns and lower values of the age at which exposure achieves its maximum both resulted in a somewhat higher pretreatment mf prevalence, but had little impact on the observed value after treatment. The variability in $\mathrm{mf}$ counts determined the probability of false-negative outcomes in mf counts, but not the underlying true level of infection. Its influence was largest in the pretreatment situation. The $\mathrm{mf}$ prevalence was somewhat lower in a younger population. The impact of mass treatment was strongly reduced when we assumed lower coverage, systematic compliance, or a lower treatment effect on adult worms. The amount of variability in the latter effect was not very important, as long as the variation occurred at random. However, if drug efficacy varied systematically between persons (so that some people always respond poorly, while others might have a good response), the overall impact of mass treatment was substantially reduced.

\section{DISCUSSION}

With the advancement of the Global Programme to Eliminate Lymphatic Filariasis, there is a growing demand for models that predict the long-term impact 

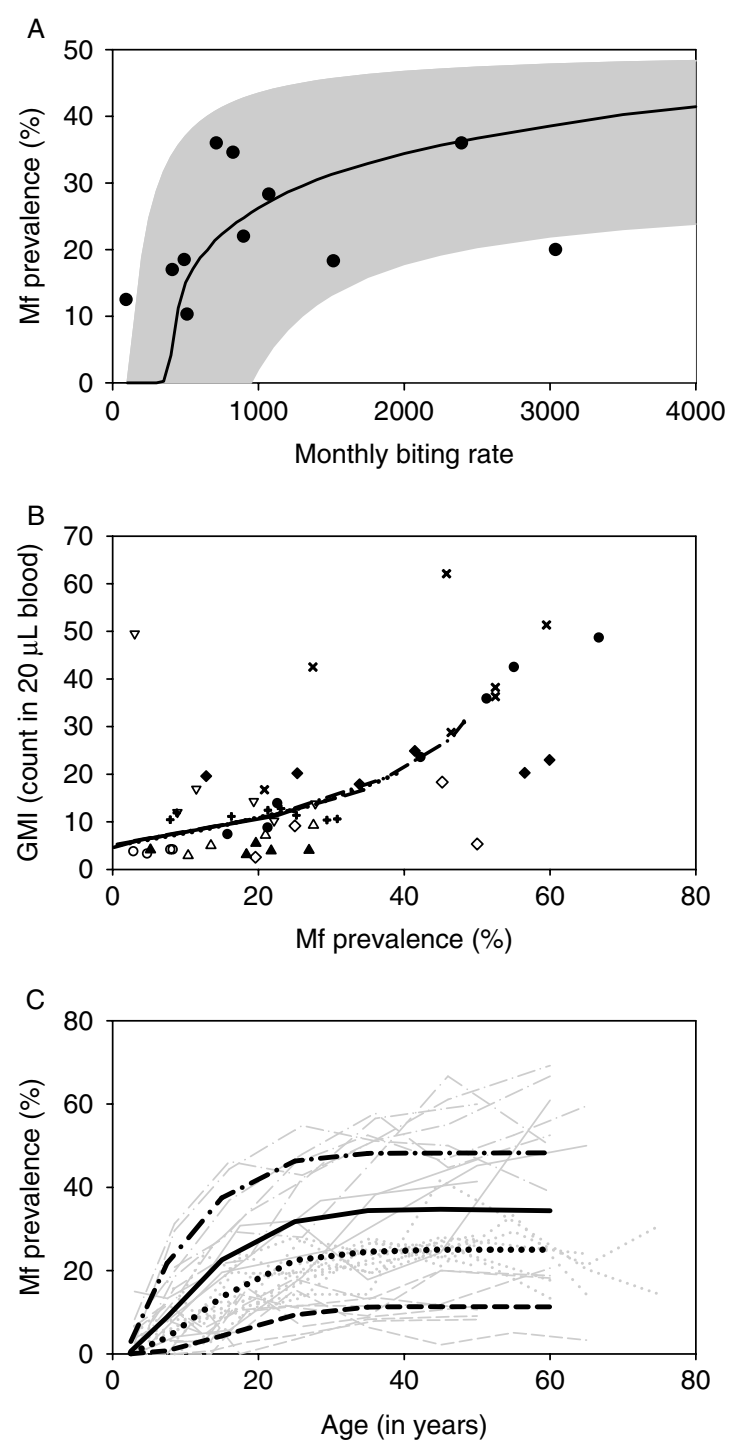

Fig. 3. Comparison of model outcomes (based on nominal parameter values, Table 1) with data collated from literature. A: Relationship between monthly biting rate $(\mathrm{mbr})$ and overall $\mathrm{mf}$ prevalence in the population. The solid line corresponds to model predictions, while the markers represent data presented in Table 2.

The grey-shaded area shows the range of possible model outcomes if time-dependent or measurement error variation in the $m b r$ and sampling variation in $\mathrm{mf}$ prevalence is taken into account (see Materials and Methods for further explanation). B: Relationship between observed $\mathrm{mf}$ prevalence and geometric mean $\mathrm{mf}$ intensity (GMI) in $20 \mu \mathrm{L}$ of blood, based on age-specific data. The overlapping lines show the model-predicted relation for monthly biting rates of 500, 750, 1000 and 2000. The markers show the observations; observations that were made in different age groups from the same community share the same symbol. C: Relationship between $\mathrm{mf}$ prevalence and host age. The thin grey lines show the observed age-patterns in different communities. Different line types were used for villages with very low (dashed), low (dotted), intermediate (solid) or high (dot-dashed) overall $\mathrm{mf}$ prevalence. The thick black lines of the same type show the corresponding model predictions which were obtained with $m b r$ of 400,500 , 750 and 2000 respectively. of control measures. We quantified the LYMFASIM simulation model (Plaisier et al. 1998) for use in African villages where Anopheles species act as main vectors, using a wide variety of reported data. Particular effort was made to test whether the model adequately captured general epidemiological patterns and differences between communities. By varying the average monthly biting rate within a realistic range (of about 100 to 4000 bites per person per month), we could simulate the entire range of observed $\mathrm{mf}$ prevalence levels, which ranged up to $40 \%$. The relationship between $\mathrm{mf}$ prevalence and geometric mean $\mathrm{mf}$ intensity in the $\mathrm{mf}$-positives, as well as the general age-patterns of $\mathrm{mf}$ prevalence matched with observations.

\section{Model behaviour}

We performed large numbers of simulations to examine whether the model behaved as expected and to provide insight into the influence of the many model parameters on the predictions. The modelpredicted trends in $\mathrm{mf}$ prevalence during and after a 6-year mass treatment programme show that the elimination prospects are best in areas with low biting rates and low pre-treatment endemicity levels. The probability and rate of recrudescence after stopping treatment increase with higher biting rate and pre-treatment endemicity levels. These predictions are plausible, but remain to be validated against observed data (see below).

The sensitivity analysis provides much information about the effects of parameter values. Adjusting the success ratio, average worm burden, rate of $\mathrm{mf}$ production per female worm, and average $\mathrm{mf}$ lifespan resulted in major changes in the predicted pre-treatment $\mathrm{mf}$ prevalence, implying that the predictions are no longer in agreement with the data of Fig. 3A and that post-treatment predictions are not valid. This does not necessarily mean that the alternative parameters values are unrealistic: a better fit might be obtained by adjusting the fitted or other model parameters.

Our sensitivity analysis confirmed the importance of density dependence assumptions as reported by others (Duerr et al. 2005). We have paid particular attention to the quantification of the uptake curve, but some uncertainty remained about the strength of density dependence. Changing these assumptions had no impact on the predicted pre-treatment $\mathrm{mf}$ prevalence level or the goodness of fit in Fig. 3 (not shown). Yet, it strongly influenced the predicted post-treatment prevalence 20 years later. Thus, the remaining uncertainty about the strength of density dependence hinders accurate predictions of longterm effects of mass treatment. We also confirmed the importance of variability in exposure to mosquito bites for elimination prospects (Duerr et al. 2005). A higher degree of variability causes stronger 
Table 2. List of published studies that provide information about both the monthly biting rate and $\mathrm{mf}$ prevalence levels in African communities where Anopheles acts as main vector for lymphatic filariasis

\begin{tabular}{|c|c|c|c|c|c|c|}
\hline Reference & $\begin{array}{l}\text { Mosquito } \\
\text { species }\end{array}$ & Country & Location & $\begin{array}{l}\text { Average } \\
\text { MBR* }\end{array}$ & Mf diagnosed & $\begin{array}{l}\text { Mf } \\
\text { prevalence }\end{array}$ \\
\hline (Kuhlow and Zielke, 1978) & A.f., A.g. & Liberia & Bolilo & 1514 & n.r. & $18 \cdot 3 \%$ \\
\hline (Kuhlow and Zielke, 1978) & A.f., A.g. & Liberia & Gbandu & 3038 & n.r. & $20 \cdot 0 \%$ \\
\hline (Kuhlow and Zielke, 1978) & A.f., A.g. & Liberia & Kaikatown & 510 & n.r. & $10 \cdot 3 \%$ \\
\hline (Kuhlow and Zielke, 1978) & A.f., A.g. & Liberia & Grahntown & 92 & n.r. & $12 \cdot 5 \%$ \\
\hline $\begin{array}{l}\text { (Wijers and Kiilu, 1977); } \\
\text { (Wijers and Kinyanjui, } \\
\text { 1977) }\end{array}$ & A.f., A.g. & Kenya & Jaribuni & 898 & $\begin{array}{l}\text { Counting chamber } \\
(100 \mu \mathrm{L})\end{array}$ & $22 \cdot 0 \%$ \\
\hline (McMahon et al. 1981) & A.f., A.g., C.q. & Tanzania & Tawalani & 1071 & $\begin{array}{l}\text { DEC-provocative test } \\
\text { and counting chamber } \\
(100 \mu \mathrm{L})\end{array}$ & $28 \cdot 3 \%$ \\
\hline (McMahon et al. 1981) & A.f., A.g., C.q. & Tanzania & Machui & 491 & $\begin{array}{l}\text { DEC-provocative test } \\
\text { and counting chamber } \\
(100 \mu \mathrm{L})\end{array}$ & $18 \cdot 5 \%$ \\
\hline (Bushrod, 1979) & A.f., A.g. & Tanzania & Kwale & 409 & n.r. & $17 \cdot 0 \%$ \\
\hline $\begin{array}{l}\text { (Maasch, 1973; Brengues } \\
\text { et al. 1968) }\end{array}$ & A.f., A.g. & $\begin{array}{l}\text { Burkina } \\
\text { Faso }\end{array}$ & Tingrela & 711 & n.r. & $36 \cdot 0 \%$ \\
\hline (Maasch, 1973) & A.f., A.g., A.m. & Liberia & Bassa Point & 825 & $\begin{array}{l}\text { Blood smear }(3 \times 20 \mu \mathrm{L} \\
\text { finger prick night blood })\end{array}$ & $34 \cdot 6 \%$ \\
\hline (Maasch, 1973) & A.f., A.g., A.m. & Liberia & Cowfarm & 2393 & $\begin{array}{l}\text { Blood smear }(3 \times 20 \mu \mathrm{L} \\
\text { finger prick night blood })\end{array}$ & $36 \cdot 0 \%$ \\
\hline
\end{tabular}

Abbreviations : A.f. $=$ Anopheles funestus; A.g. =Anopheles gambiae; C.q. =Culex quinquefasciatus; A.m. =Anopheles melas; $\mathrm{MBR}=$ monthly biting rate; n.r. = not reported.

* The average MBR is the mean biting rate over a period of 1 year, calculated as $1 / 12 *$ annual biting rate. The annual biting rate was estimated from landing catches, which were performed with regular intervals in a period of 12 months.

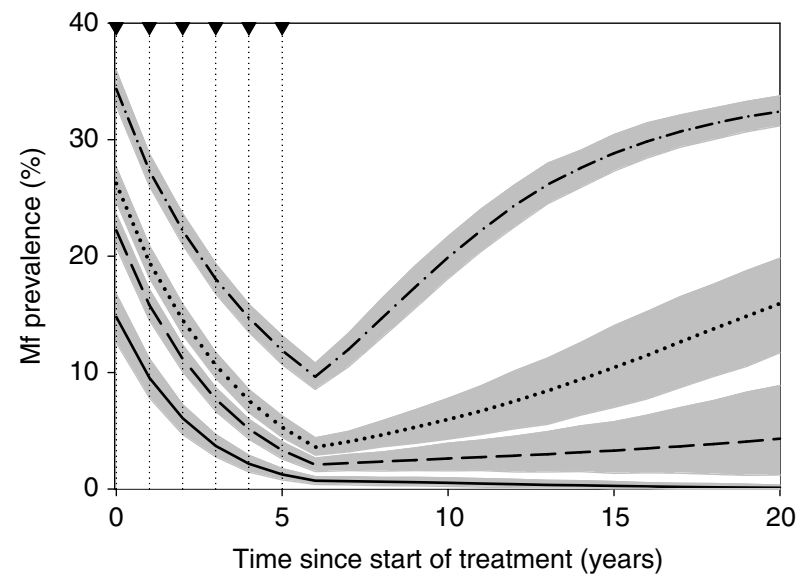

Fig. 4. Model-predicted trends in $\mathrm{mf}$ prevalence during and after a 6 -year mass treatment programme. Treatment takes place in the first 6 years of the simulation with the assumptions of Table 3 . The dotted lines and arrowheads on the top-axis indicate the times of treatment. The thick lines show the average predicted trends for monthly biting rates of 500 (solid), 750 (dashed), 1000 (dotted) and 2000 (dot-dashed). The grey areas around each line indicate 5 th to 95 th percentile range of simulation results at each time. The results are based on 500 simulation runs. The trends are based on yearly measurements at $t=0,1,2, \ldots, 20$; fluctuations between these time-points are not shown.

aggregation in the distribution of the parasites over humans (some people harbouring many worms and others few or none); this increases the mating
Table 3. Parameter assumptions about mass treatment and drug efficacy

\begin{tabular}{|c|c|}
\hline Parameter & Nominal value \\
\hline Number of treatment rounds & 6 \\
\hline Coverage & $80 \%$ \\
\hline $\begin{array}{l}\text { Individual compliance to } \\
\text { treatment in subsequent rounds* }\end{array}$ & 'semi-systematic' \\
\hline $\begin{array}{l}\text { Fixed proportion of mf } \\
\text { killed by each treatment }\end{array}$ & $100 \%$ \\
\hline $\begin{array}{l}\text { Mean proportion of } \\
\text { worms killed by each treatment }\end{array}$ & $50 \%$ \\
\hline $\begin{array}{l}\text { Standard deviation of the beta } \\
\text { distribution describing the amount } \\
\text { of random variability in the fraction } \\
\text { of worms killed by treatment } \dagger\end{array}$ & $0 \cdot 2$ \\
\hline
\end{tabular}

* See Appendix 1 for explanation.

$\dagger$ The default assumption is that this variation occurs randomly between treatments. The sensitivity analysis considered the alternative assumption that variation occurs systematically between individuals and that there is no variation within individuals.

probability of worms, especially when worm numbers are low, and leads to higher risk and rates of recrudescence after stopping treatment. Differences between communities in the amount of variability result in variable elimination prospects (Dadzie et al. 2004).

As previously shown, post-control predictions depend heavily on assumed coverage and compliance patterns (Plaisier et al. 2000; Stolk et al. 2003; 

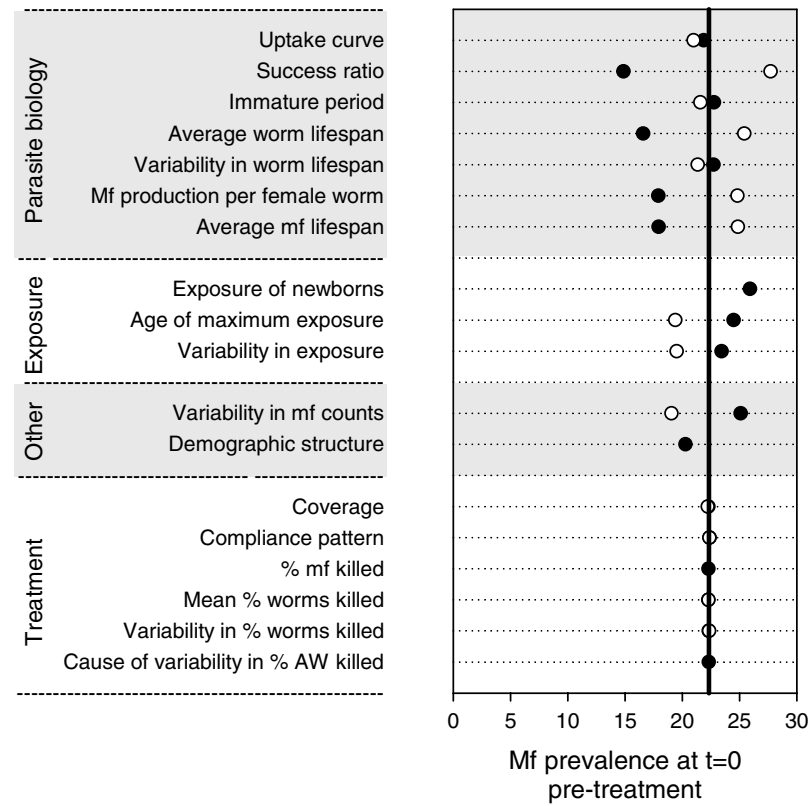

limitation; stronger facilitation sr. $0.00059,0.00132$ Ti: $5.3 ; 12$ months

TI: 6.7; 15 year less, more variability $\left[\alpha_{T 1}: 3.0,1.3\right]$ $r_{0}: 0.39 ; 0.87 \mathrm{mf}$ per $20 \mu \mathrm{L}$ per month Tmf: 6.7 months, 15 months

\section{$E_{0}: 0.40$}

$a_{\text {max }}: 13,30$ years

less, more variability $\left[\alpha_{E}: 0.39 ; 0.17\right]$

less, more variability $[k: 0.50 ; 022]$ younger population

$70 \%, 87 \%$ coverage random, systematic compliance $85 \% \mathrm{mf}$ killed

$33 \%, 75 \%$ of worms killed less, more variability [sd: $0.13 ; 0.30$ ] systematic variation between persons

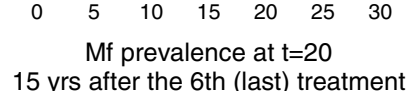

Fig. 5. Sensitivity analysis: impact of changes in parameter values and other model assumptions on the predicted mf prevalence before and after an intervention with 6 yearly rounds of mass treatment. Post-treatment mf prevalence was measured in year 20, i.e. 15 years after the 6 th (last) treatment round. The vertical black lines in each graph show the $\mathrm{mf}$ prevalence levels that were predicted by the model with nominal parameter values (Table 1). Markers show the results obtained under alternative assumptions. On the left side of the graph we provide descriptive labels for the parameters or assumptions concerned. On the right side of the graph we specify the alternative value for the parameters concerned, with the 1 st value corresponding to the black bullet and the 2 nd value (if available) to the white bullet. See Materials and Methods for considerations in choosing alternative values.

Michael et al. 2004). This underlines the importance of assessing their actual values for evaluation of treatment programmes. The effects of treatment on adult worms are also very important, and uncertainty about this affects our ability to predict accurately post-treatment trends in infection.

\section{Model validation}

A strength of our validation approach is the comparison of the model predictions to data from a range of different communities. This helped to identify both the general pattern and realistic deviations. Deviations from the model-predicted average relationships can be large. See for example Fig. 3A. The model predicts a clear transmission threshold in the biting rate: if the average monthly biting rate drops below the value of 400 , the basic reproduction ratio $\left(R_{0}\right)$ becomes too low and the infection will die out $\left(R_{0}<1\right)$. Such a threshold is theoretically plausible and our estimate was of the same order of magnitude as an earlier published estimate (Michael et al. 2006). However, the threshold pattern is not clearly visible in the data. Several reasons may be given as explanations for this. Firstly, the data are subject to measurement, sampling, or timedependent variation. The latter is particularly relevant because trends and fluctuations in biting rates are not immediately reflected in $\mathrm{mf}$ prevalence levels. Because of these factors, the observations do not lie on the predicted curve, but can lie anywhere in the grey-shaded area of Fig. 3A. Secondly, local conditions can differ from the average conditions assumed in our model (e.g. with respect to variability in exposure, the age-structure of the population or anthropophagy of the local vector), leading to a different transmission threshold (Basáñez et al. 2002; Duerr et al. 2005).

The model predictions were only compared with cross-sectional data from treatment-naïve communities. A next step is to compare model predictions with longitudinal, post-treatment data. Evaluation data from the ongoing mass treatment programmes will be very helpful. Data collected during the first treatment years may not yet be very powerful for validation, because the model parameters are not uniquely identifiable. For example, effective mass treatment leads to a strong reduction in transmission. Uncertainty about treatment parameters (coverage, compliance, drug efficacy) precludes the accurate quantification of the remaining transmission. The most informative data for validating the underlying biological assumptions are probably those that are collected after cessation of prematurely interrupted or unsuccessful elimination campaigns: from the rate of recrudescence after cessation we can learn much more than from the rate of decline during mass treatment. Such data are available only for a few African villages (Meyrowitsch, Simonsen and Magesa, 2004 $a, b)$. It would be interesting to test the 
model against these data, but more data are needed to understand the general trends and possible deviations depending on local factors. Since the GPELF strives to achieve success in elimination programmes, such data will probably remain scarce for some time.

\section{Uncertainty}

One of the uncertain aspects in models for LF transmission is the role of acquired immunity. While strong acquired immunity was included in the Pondicherry model (Subramanian et al. 2004), we found that evidence from the African continent is not consistent with this type of immunity as a strong regulatory factor of parasite population abundance (Stolk et al. 2004). The difference between the Pondicherry and Africa model is somewhat unsatisfactory: it is rather unlikely that this mechanism plays a role in one region, but not in another. The new challenge is to define whether a model without acquired immunity can explain the observed patterns from Pondicherry if we take account of specific local conditions. In our earlier paper we discussed possible explanations (Stolk et al. 2004).

The discussion about acquired immunity points at a more general problem in modelling LF transmission, i.e. our incomplete understanding of the transmission dynamics, the nature and magnitude of regulatory processes, and the effects of treatment. For example, we rejected the hypothesis that strong acquired immunity leads to a lower $\mathrm{mf}$ prevalence in elderly individuals, but we cannot exclude the operation of other regulatory immune processes (Woolhouse, 1992). Similarly, we lack knowledge about other factors that could influence the predictions, such as the occurrence of density dependence in the various processes of the parasite's life cycle (Duerr et al. 2005; Churcher, Filipe and Basáñez, 2006), or the possibility that parasites become resistant against the antifilarial drugs (McCarthy, 2005; Schwab et al. 2005, 2007). We can also question the assumption that biological parameters such as the lifespan of adult worms and $\mathrm{mf}$ do not vary between locations. In the absence of evidence about these factors or data to validate assumptions, we kept the model parsimonious, trusting that the model captures the critical processes. Yet, this underlines the need to validate the model against longitudinal, post-treatment data, when they become available.

\section{Application of the model}

The model can be a useful tool for decision support in LF elimination programmes in the African region. For example, the model can help to determine the coverage and number of treatment rounds required for LF elimination under the different circumstances that occur in the African region using earlier published methods (Winnen et al. 2002; Stolk et al.
2003). Further, detailed analysis of predicted trends after cessation of mass treatment can elucidate how the probability of achieving elimination depends on outcomes of epidemiological surveys in the end phase of treatment programmes and early years of follow-up. This will help to determine criteria for the cessation of mass treatment and to design surveillance schemes to monitor for possible recrudescence. Clearly, all predictions need to be accompanied by critical assessment of uncertainty. Making this uncertainty explicit can contribute to better and prudent decision-making.

\section{Conclusion}

In conclusion, we have developed a generic model for LF transmission by Anopheles mosquitoes in Africa, which captures the most important factors of LF dynamics and can easily be adjusted to specific circumstances by changing assumptions about exposure to mosquito bites. Its predictions are consistent with cross-sectional parasitological and entomological data. Although further validation against longitudinal, post-treatment data is required, the model already provides an important tool for decisionmaking in LF elimination programmes. The model can help to assess when ongoing elimination activities in African populations can be stopped and to design surveillance schemes. In view of the rapid expansion of the Global Programme to Eliminate Lymphatic Filariasis, these issues need to be addressed urgently.

\section{ACKNOWLEDGEMENTS}

We thank Dr Daniel Boakye for sharing data about the uptake of infection by Anopheles mosquitoes and for access to some unpublished data about time changes in annual biting rates. We thank Dr Johnny Gyapong for fruitful discussions about need for and potential applications of models for LF transmission in Africa in an early stage of the project. This investigation received financial support from the UNICEF/UNDP/World Bank/WHO Special Programme for Research and Training in Tropical Diseases (TDR).

\section{REFERENCES}

Akogun, O. B. (1991). Filariasis in Gongola State Nigeria. I : Clinical and parasitological studies in Mutum-Biyu district. Fournal of Hygiene, Epidemiology, Microbiology and Immunology, 35, 383-393.

Anosike, J. C., Nwoke, B. E., Ajayi, E. G., Onwuliri, C. O., Okoro, O. U., Oku, E. E., Asor, J. E., Amajuoyi, O. U., Ikpeama, C. A., Ogbusu, F. I. and Meribe, C. O. (2005). Lymphatic filariasis among the Ezza people of Ebonyi State, eastern Nigeria. Annals of Agricultural and Environmental Medicine 12, 181-186.

Armitage, P. and Berry, G. (1994). Statistical Methods in Medical Research. Third edition. Oxford: Blackwell Scientific Publications. 
Basáñez, M. G., Collins, R. C., Porter, C. H., Little, M. P. and Brandling-Bennett, D. (2002). Transmission intensity and the patterns of Onchocerca volvulus infection in human communities. American Fournal of Tropical Medicine and Hygiene 67, 669-679.

Boakye, D. A., Wilson, M. D., Appawu, M. A. and Gyapong, J. (2004). Vector competence, for Wuchereria bancrofti, of the Anopheles populations in the Bongo district of Ghana. Annals of Tropical Medicine and Parasitology 98, 501-508. doi: 10.1179/000349804225003514.

Brengues, J. (1975). La filariose de bancroft en Afrique de l'Ouest. In Mémoires Orstom, Vol. 79, 299pp. Office de la Recherche Scientifique et Technique Outre-Mer (ORSTOM).

Brengues, J., Subra, R. and Bouchite, B. (1969). Etude parasitologique, clinique et entomologique sur la filariose de Bancroft dans le sud du Dahomey et du Togo. Cahiers ORSTOM, série Entomologie médicale et Parasitologie 7, 279-305.

Brengues, J., Subra, R., Mouchet, J. and Nelson, G. S. (1968). La transmission de Wuchereria bancrofti Cobbold en Afrique occidentale. Étude préliminaire d'un foyer de savane nord-guinéenne. Bulletin of the World Health Organization 38, 595-608.

Bryan, J. H. and Southgate, B. A. (1988a). Factors affecting transmission of Wuchereria bancrofti by anopheline mosquitoes. 1. Uptake of microfilariae. Transactions of the Royal Society of Tropical Medicine and Hygiene 82, 128-137.

Bryan, J. H. and Southgate, B. A. (1988b). Factors affecting transmission of Wuchereria bancrofti by anopheline mosquitoes. 2. Damage to ingested microfilariae by mosquito foregut armatures and development of filarial larvae in mosquitoes. Transactions of the Royal Society of Tropical Medicine and Hygiene 82, 138-145.

Bushrod, F. M. (1979). Studies on filariasis transmission in Kwale, a Tanzanian coastal village, and the results of mosquito control measures. Annals of Tropical Medicine and Parasitology 73, 277-285.

Chan, M. S., Srividya, A., Norman, R. A., Pani, S. P., Ramaiah, K. D., Vanamail, P., Michael, E., Das, P. K. and Bundy, D. A. (1998). Epifil: a dynamic model of infection and disease in lymphatic filariasis. American Fournal of Tropical Medicine and Hygiene $\mathbf{5 9}$, 606-614.

Churcher, T. S., Filipe, J. A. and Basáñez, M. G. (2006). Density dependence and the control of helminth parasites. Fournal of Animal Ecology 75, 1313-1320. doi:10.1111/j.1365-2656.2006.01154.x.

Dadzie, K. Y., Basáñez, M. G. and Richards, F. O., Jr. (2004). Epidemiology, parasite biology, modeling. In Towards a strategic plan for research to support the global program to eliminate lymphatic filariasis. Summary of immediate needs and opportunities for research on lymphatic filariasis. Philadelphia, Pennsylvania, USA, December 9-10. 2003. American Fournal of Tropical Medicine and Hygiene 71, 22-23.

Duerr, H. P., Dietz, K. and Eichner, M. (2005). Determinants of the eradicability of filarial infections : a conceptual approach. Trends in Parasitology 21, 88-96. doi: 10.1016/j.pt.2004.11.011.

Gyapong, J. O., Badu, J. K., Adjei, S. and Binka, F. (1993). Bancroftian filariasis in the Kassena Nankana District of the upper east region of Ghana: a preliminary study. Fournal of Tropical Medicine and Hygiene 96, 317-322.

Gyapong, J. O., Omane-Badu, K. and Webber, R. H. (1998). Evaluation of the filter paper blood collection method for detecting $\mathrm{Og} 4 \mathrm{C} 3$ circulating antigen in bancroftian filariasis. Transactions of the Royal Society of Tropical Medicine and Hygiene 92, 407-410.

Gyapong, J. O. and Twum-Danso, N. A. (2006). Editorial: Global elimination of lymphatic filariasis : fact or fantasy? Tropical Medicine and International Health 11, 125-128. doi: 10.1111/j.1365-3156.2005.01542.x.

Habbema, J. D. F., De Vlas, S. J., Plaisier, A. P. and Van Oortmarssen, G. J. (1996). The microsimulation approach to epidemiologic modeling of helminthic infections, with special reference to schistosomiasis. American Fournal of Tropical Medicine and Hygiene 55, 165-169.

Juminer, B., Diallo, S. and Diagne, S. (1971). Le foyer de filariose lymphatique du secteur de Sandiara (Sénégal). I. Evaluation de l'endémicité. Archives de l'Institut Pasteur de Tunis 48, 231-246.

Kalbfleish, J. G. (1979). Probability and Statistical Inference, II. Springer Verlag, New York.

Kuhlow, F. and Zielke, E. (1978). Dynamics and intensity of Wuchereria bancrofti transmission in the savannah and forest regions of Liberia. Tropenmedizin und Parasitologie 29, 371-381.

Maasch, H. J. (1973). Quantitative Untersuchungen zur Übertragung von Wuchereria bancrofti in der Küstenregion Liberias. Zeitschrift für Tropenmedizin und Parasitologie 24, 419-434.

McCarthy, J. (2005). Is anthelmintic resistance a threat to the program to eliminate lymphatic filariasis? American Fournal of Tropical Medicine and Hygiene 73, 232-233.

McFadzean, J. A. (1954). Filariasis in Gambia and Casamance, West Africa. Transactions of the Royal Society of Tropical Medicine and Hygiene 48, 267-273.

McGregor, I. A., Hawking, F. and Smith, D. A. (1952). The control of filariasis with hetrazan. A field trial in a rural village (Keneba) in the Gambia. British Medical Fournal ii, 908-911.

McMahon, J. E., Magayauka, S. A., Kolstrup, N., Mosha, F. W., Bushrod, F. M., Abaru, D. E. and Bryan, J. H. (1981). Studies on the transmission and prevalence of Bancroftian filariasis in four coastal villages of Tanzania. Annals of Tropical Medicine and Parasitology 75, 415-431.

Meyrowitsch, D. W., Simonsen, P. E. and Magesa, S. M. $(2004 a)$. A 26-year follow-up of bancroftian filariasis in two communities in north-eastern Tanzania. Annals of Tropical Medicine and Parasitology 98, 155-169. doi: 10.1179/000349804225003172.

Meyrowitsch, D. W., Simonsen, P. E. and Magesa, S. M. $(2004 b)$. Long-term effect of three different strategies for mass diethylcarbamazine administration in bancroftian filariasis: follow-up at 10 years after treatment. Transactions of the Royal Society of Tropical Medicine and Hygiene 98, 627-634. doi: 10.1016/ j.trstmh.2004.01.004. 
Michael, E., Malecela-Lazaro, M. N., Kabali, C., Snow, L. C. and Kazura, J. W. (2006). Mathematical models and lymphatic filariasis control: endpoints and optimal interventions. Trends in Parasitology 22, 226-233.

Michael, E., Malecela-Lazaro, M. N., Simonsen, P. E., Pedersen, E. M., Barker, G., Kumar, A. and Kazura, J. W. (2004). Mathematical modelling and the control of lymphatic filariasis. Lancet Infectious Diseases 4, 223-234. doi: 10.1016/S1473-3099(04)00973-9.

Plaisier, A. P., Cao, W. C., van Oortmarssen, G. J. and Habbema, J. D. (1999). Efficacy of ivermectin in the treatment of Wuchereria bancrofti infection: a model-based analysis of trial results. Parasitology 119, 385-394. doi: 10.1017/S0031182099004783.

Plaisier, A. P., Stolk, W. A., van Oortmarssen, G. J. and Habbema, J. D. (2000). Effectiveness of annual ivermectin treatment for Wuchereria bancrofti infection. Parasitology Today 16, 298-302. doi: 10.1016/ S0169-4758(00)01691-4.

Plaisier, A. P., Subramanian, S., Das, P. K., Souza, W., Lapa, T., Furtado, A. F., Van der Ploeg, C. P. B., Habbema, J. D. F. and Van Oortmarssen, G. J. (1998). The LYMFASIM simulation program for modeling lymphatic filariasis and its control. Methods of Information in Medicine 37, 97-108.

Ripert, C., Eono, P., Eono, D., Tribouley, J., Appriou, M. and Issoufa, H. (1982). Etude epidemiologique de la bancroftose dans la Vallee du Logone (Nord Cameroun). Medecine Tropicale 42, 59-66.

Rochet, M. J. (1990). A simple deterministic model for bancroftian filariasis transmission dynamics. Tropical Medicine and Parasitology 41, 225-233.

Schwab, A. E., Boakye, D. A., Kyelem, D. and Prichard, R. K. (2005). Detection of benzimidazole resistance-associated mutations in the filarial nematode Wuchereria bancrofti and evidence for selection by albendazole and ivermectin combination treatment. American Fournal of Tropical Medicine and Hygiene 73, 234-238.

Schwab, A. E., Churcher, T. S., Schwab, A. J., Basáñez, M. G. and Prichard, R. K. (2007) An analysis of the population genetics of potential multi-drug resistance in Wuchereria bancrofti due to combination chemotherapy. Parasitology 134, 1025-1040.

Smith, T., Maire, N., Dietz, K., Killeen, G. F., Vounatsou, P., Molineaux, L. and Tanner, M. (2006). Relationship between the entomologic inoculation rate and the force of infection for Plasmodium falciparum malaria. American Fournal of Tropical Medicine and Hygiene 75, 11-18.

Smith, T., Maire, N., Ross, A., Penny, M., Chitnis, N., Schapira, A., Studer, A., Genton, B., Lengeler, C., Tediosi, F., De Savigny, D. and Tanner, M. (2008). Towards a comprehensive simulation model of malaria epidemiology and control. Parasitology. doi : 10.1017/S0031182008000371.

Snow, L. C., Bockarie, M. J. and Michael, E. (2006). Transmission dynamics of lymphatic filariasis: vector-specific density dependence in the development of Wuchereria bancrofti infective larvae in mosquitoes.
Medical and Veterinary Entomology 20, 261-272. doi: 10.1111/j.1365-2915.2006.00629.x.

Snow, L. C. and Michael, E. (2002). Transmission dynamics of lymphatic filariasis: density-dependence in the uptake of Wuchereria bancrofti microfilariae by vector mosquitoes. Medical and Veterinary Entomology 16, 409-423. doi: 10.1046/j.1365-2915.2002.00396.x.

Southgate, B. A. (1992). The significance of low density microfilaraemia in the transmission of lymphatic filarial parasites. Fournal of Tropical Medicine and Hygiene 95, 79-86.

Southgate, B. A. and Bryan, J. H. (1992). Factors affecting transmission of Wuchereria bancrofti by anopheline mosquitoes. 4. Facilitation, limitation, proportionality and their epidemiological significance. Transactions of the Royal Society of Tropical Medicine and Hygiene 86, 523-530.

Stolk, W. A., de Vlas, S. J. and Habbema, J. D. (2006). Advances and challenges in predicting the impact of lymphatic filariasis elimination programmes by mathematical modelling. Filaria Fournal 5, 5. doi: 10.1186/1475-2883-5-5.

Stolk, W. A., De Vlas, S. J. and Habbema, J. D. F. (2005). Anti-Wolbachia treatment for lymphatic filariasis. Lancet 365, 2067-2068.

Stolk, W. A., Ramaiah, K. D., Van Oortmarssen, G. J., Das, P. K., Habbema, J. D. F. and De Vlas, S. J. (2004). Meta-analysis of age-prevalence patterns in lymphatic filariasis: no decline in microfilaraemia prevalence in older age groups as predicted by models with acquired immunity. Parasitology 129, 605-612. doi: 10.1017/S0031182004005980.

Stolk, W. A., Subramanian, S., Oortmarssen, G. J., Das, P. K. and Habbema, J. D. F. (2003). Prospects for elimination of bancroftian filariasis by mass drug treatment in Pondicherry, India: a simulation study. Fournal of Infectious Diseases 188, 1371-1381. doi: 10.1086/378354.

Subramanian, S., Stolk, W. A., Ramaiah, K. D., Plaisier, A. P., Krishnamoorthy, K., Van Oortmarssen, G. J., Amalraj, D., Habbema, J. D. F. and Das, P. K. (2004). The dynamics of Wuchereria bancrofti infection: a model-based analysis of longitudinal data from Pondicherry, India. Parasitology 128, 467-482. doi: 10.1017/S0031182004004822.

US Census Bureau (2004). International Population Reports WP/02. Global Population Profile: 2002. US. Government Printing Office, Washington, DC.

Wijers, D. J. and Kiilu, G. (1977). Bancroftian filariasis in Kenya III. Entomological investigations in Mambrui, a small coastal town, and Jaribuni, a rural area more inland (Coast Province). Annals of Tropical Medicine and Parasitology 71, 347-359.

Wijers, D. J. and Kinyanjui, H. (1977). Bancroftian filariasis in Kenya II. Clinical and parasitological investigations in Mambrui, a small coastal town, and Jaribuni, a rural area more inland (Coast Province). Annals of Tropical Medicine and Parasitology 71, 333-345.

Winnen, M., Plaisier, A. P., Alley, E. S., Nagelkerke, N. J., van Oortmarssen, G., Boatin, B. A. and Habbema, J. D. (2002). Can ivermectin mass treatments eliminate onchocerciasis in Africa? Bulletin of the World Health Organization 80, 384-391. 
Woolhouse, M. E. (1992). A theoretical framework for the immunoepidemiology of helminth infection. Parasite Immunology 14, 563-578.

World Health Organization (1992). Lymphatic filariasis: the disease and its control. Fifth report of the WHO Expert Committee on Filariasis.

APPENDIX 1. THE LYMFASIM SIMULATION MODEL

\section{Simulation technique}

LYMFASIM is based on the technique of stochastic microsimulation (Habbema et al. 1996). This technique is characterized by the simulation of individual life histories of fictitious persons, who in aggregate constitute the population of interest. The computer program tracks expected changes over time in the population composition and the relevant characteristics of each individual.

\section{Model structure}

The model simulates the demographic processes that drive population changes. Births and deaths are modelled as stochastic events in the life course of individuals. The expected number of newborns per time step depends on the number of females per age group and age-specific fertility rates. Random numbers define the realized number of newborns entering the population per time step. The age of death varies between individuals; it is defined as soon as a person enters the population by drawing a random variate from a life table. Immigration and emigration are not considered in the LYMFASIM model.

Each simulated individual has a number of characteristics, which define personal risk factors and behaviours that are relevant for transmission and control. Some of these characteristics are fixed, such as gender, attractiveness to mosquitoes, or willingness to comply with treatment. They are determined by randomly drawing a value from prespecified probability distributions. Other characteristics can change during the course of a simulation, such as the age-dependent fertility rates and exposure to mosquitoes. Because of their personal characteristics, individuals may be predisposed to heavy or light infections. The infection status is the most important characteristic of human individuals. LYMFASIM simulates the transmission of parasites from person to person and tracks changes in the number of worms per individual.

A schematic representation of the variables and processes involved in transmission is provided in Fig. 1. Because LYMFASIM uses one-month time steps, all rates are expressed per month. The monthly transmission potential $\left(m t p_{i}\right)$ reflects the number of
World Health Organization Technical Report Series

821, 1-71.

World Health Organization (2006). Global

Programme to Eliminate Lymphatic

Filariasis. Weekly Epidemiological Record 81, 221-232.

L3 larvae that are released to a person per month. On average, only a small proportion (called the success ratio, $s r$ ) of the released larvae will survive to develop further into adult worms; a chance process defines how many L3 larvae survive per month. The life course of surviving worms is simulated at individual worm level. Worms are immature during a period $T i$ and their average lifespan is $T l$. The lifespan varies between worms according to a Weibull distribution with shape parameter $\alpha_{T l}$. We assume that all adult females are inseminated and produce microfilariae $(\mathrm{mf})$, if at least one male worm is present in the human body. Parameter $r_{0}$ gives the mf production per female worm, expressed as the number of $\mathrm{mf}$ per month and per $20 \mu \mathrm{L}$ of peripheral blood. Mf have a mean lifespan Tmf and their monthly survival is given by $1-1 / T m f$. Mf are not simulated at the individual level; the model merely calculates the average $\mathrm{mf}$ density in the blood per individual (expressed in mf per $20 \mu \mathrm{L}$ night finger prick blood). LYMFASIM has the option to include acquired immunity, which either reduces the probability of L3 larvae to develop into adult worm or reduces the $\mathrm{mf}$ output by female adult worms. Both mechanisms result in a lower mf count in elderly compared to young adults. As explained in the main text, acquired immunity is not included in the current model.

The 'uptake curve' (in this case given by a mathematical function with parameters $a, b$, and $c$ ) describes the deterministic relation between the $\mathrm{mf}$ density in the human blood of person $i$ and the average number of L3 larvae that develop in a mosquito after feeding on that person $\left(L 3_{i}\right)$. The average number of L3 larvae taken up by mosquitoes is given by the weighted average of the uptake from all individuals, the weights reflecting the relative exposure of each individual to mosquito bites ( $E_{i}$, see below). This average number is multiplied by a factor $v$ to calculate the average number of L3 larvae that is released per bite, $\overline{L 3}$. The factor $v$ accounts for the proportion of L3 that is lost due to mosquito death and the proportion of L3 that does not leave the mosquito when it bites.

The relative exposure of an individual $\left(E_{i}\right)$ indicates how many mosquito bites a person gets per month. It is expressed as a fraction of the average number of mosquito bites received per adult male per month (monthly biting rate, $m b r$ ). LYMFASIM 
accounts for age (and optional sex) variation in exposure and random variation in individuals' attractiveness for mosquitoes. Here we adopt the common assumption that exposure increases with body surface during growth in childhood and stabilizes in adults (Duerr et al. 2005; Smith et al. 2006). We approximate this by a linear increase in relative exposure from $E_{0}$ at birth to the adult (maximum) level that is achieved at age $a_{\text {max }}$. The random, not age-related variability in exposure is described by a gamma distribution with shape parameter $\alpha_{E}$ and mean 1. An individual's relative exposure does not only determine his/her contribution to the mean L3-load of mosquitoes, but also the number of L3-larvae received: the monthly transmission potential $\left(m t p_{i}\right)$ is calculated as the mean number of L3 larvae released per mosquito bite $(\overline{L 3}$, see above) multiplied by the $m b r$ and the individual's relative exposure $\left(E_{i}\right)$. We assume that the $m b r$ is constant over time, ignoring seasonal variation and other time trends.

\section{Control strategies}

To simulate the impact of mass drug administration, the user must specify the exact moments of treatment (year, month), the drug or administration regimen applied with its efficacy, the fraction of people treated per round (coverage), and the compliance pattern.

The three main effects of treatment are: (1) a fraction of adult worms is killed; (2) a fraction of female adult worms is permanently sterilized (i.e. they stop producing $\mathrm{mf}$ ); and (3) a fraction of $\mathrm{mf}$ is killed. The fraction of parasites affected can be constant or can vary according to a chosen probability distribution function. In addition, for each of the three mechanisms, the user may specify a fraction of treated patients with no or full effect of treatment (i.e. the fraction of parasites affected is respectively 0 or 1 ). All stochastic variables related to the effects of treatment are by default assumed to be independent and to be generated for each person at each treatment. As an alternative, the treatment efficacy can be attributed as a fixed characteristic to an individual, who in that case always responds in the same way to treatment. Temporal reductions in the $\mathrm{mf}$ production can also be simulated (Plaisier et al. 1998), but these are not included here.

The compliance pattern describes the tendency of persons to participate in repeated treatment rounds. In case of random compliance, all individuals have the same probability to be treated (equal to the fraction covered). In case of systematic compliance, each person in the population is characterized by an invariable compliance factor (a random number between 0 and 1 ), which results in a treatment probability of either 1 (for compliance factor $\leqslant$ coverage) or 0 (for compliance factor $>$ coverage). Consequently, if coverage is constant over time, some individuals will always be treated while the remaining persons are never treated. In the case of semi-systematic compliance pattern, the compliance factor indicates a person's tendency to participate. Random numbers define whether an individual is actually treated or not. The latter pattern is presumably most realistic (Plaisier et al. 2000).

LYMFASIM also allows the simulation of selective treatment. In that case, treatment is only provided to those persons who were Mf positive in the most recent survey (which may take place in the same month as treatment, see below). Coverage and compliance play no role. Vector control can be modelled as a percentage reduction of the monthly biting rate during a specified period. The number of such periods, their duration and the reduction in monthly biting rate can be chosen.

\section{Model output}

At chosen times surveys can be simulated to determine the $\mathrm{mf}$ counts for all individuals in the population. We assume that this is done by microscopic examination of a $20 \mu \mathrm{L}$ night blood smear. The counts are variable and are assumed to follow a negative binomial distribution with clumping factor $k$ and the simulated $\mathrm{mf}$ density as mean expected outcome. The results can be summarized by different population-level indicators of infection: the $\mathrm{mf}$ prevalence, the geometric or arithmetic mean number of mf per smear, or the frequency distribution of $\mathrm{mf}$ counts in the population. Survey results can be tabulated by age group and gender.

\section{Running the model}

The program starts by creating an initial population, with specified size and age distribution. At the start of the simulation, some people are infected via some external force of infection. The model simulates how the population develops and how the infection level and other individual characteristics change in each one-month time step. To reach an endemic equilibrium situation and a stable age structure of the population, a simulation must generally cover a period of many decades. This is called a 'burn-in' period. Since the characteristics of persons are determined by chance or change as a result of stochastic processes, the result of one simulation run represents only one of many possible outcomes. Repeated runs will give slightly different results. The variability between runs reflects natural variation in real world populations, conditional on the appropriateness of the model structure. Simulations always have to be repeated to estimate the mean outcome and gain an insight into variability. 
Table 4. Summary information about the data used for quantifying the vector uptake curve for Anopheles mosquitoes

\begin{tabular}{|c|c|c|c|c|c|}
\hline $\begin{array}{l}\text { Methods used for } \\
\text { measuring mf intensity }\end{array}$ & $\begin{array}{l}\text { Reported } \mathrm{mf} \\
\text { intensity in } \\
\mathrm{mf} / \mathrm{mL} \text { (range) }\end{array}$ & $\begin{array}{l}\text { No. of } \\
\text { batches of } \\
\text { mosquitoes } \\
\text { examined }\end{array}$ & $\begin{array}{l}\text { Mosquito } \\
\text { species }\end{array}$ & $\begin{array}{l}\text { Mean no. of } \\
\text { mosquitoes } \\
\text { dissected per } \\
\text { batch (range) }\end{array}$ & $\begin{array}{l}\text { Mean no. of } \\
\text { L3 recovered } \\
\text { from mosquitoes } \\
\text { in a batch (range) }\end{array}$ \\
\hline $\begin{array}{l}\text { (Boakye et al. 2004) } \\
\text { Mean mf count in } 9 \times 100 \mu \mathrm{L} \text { samples of } \\
\text { finger prick blood, counting chamber }\end{array}$ & $2630(0-9740)$ & 20 & A.f., A.g. & $15 \cdot 9(1-34)$ & $1 \cdot 23(0-3 \cdot 31)$ \\
\hline $\begin{array}{l}\text { (Southgate and Bryan, 1992) } \\
\text { Mf count in a } 1 \times 100 \mu \mathrm{L} \text { sample of } \\
\text { finger prick blood, counting chamber }\end{array}$ & $\begin{array}{l}1490(1300-1735) \\
1434(1190-1677) \\
1408(920-1657) \\
1367(930-1735)\end{array}$ & $\begin{array}{l}3 \\
3 \\
3 \\
3\end{array}$ & $\begin{array}{l}\text { A.g. } \\
\text { A.a. } \\
\text { A.mr. } \\
\text { A.f. }\end{array}$ & $\begin{array}{l}39 \cdot 7(\mathrm{NA}) \\
25 \cdot 3 \text { (NA) } \\
87 \cdot 7 \text { (NA) } \\
38 \cdot 7 \text { (NA) }\end{array}$ & $\begin{array}{l}0 \cdot 52(0 \cdot 28-0 \cdot 87) \\
1 \cdot 48(1 \cdot 11-1 \cdot 67) \\
1 \cdot 16(0 \cdot 79-1 \cdot 56) \\
0 \cdot 67(0 \cdot 24-1 \cdot 13)\end{array}$ \\
\hline $\begin{array}{l}\text { (Bryan and Southgate, } 1988 a, b) \\
\text { Mf count in } 1 \times 1 \mathrm{~mL} \text { venous blood } \\
\text { sample, membrane filtration; } \\
\text { sometimes: mf count in } 20 \mu \mathrm{L} \\
\text { finger prick blood }\end{array}$ & $\begin{array}{l}312(0-11400) \\
286(0-11400) \\
435(0-11400)\end{array}$ & $\begin{array}{l}20 \\
18 \\
11\end{array}$ & $\begin{array}{l}\text { A.g. } \\
\text { A.a. } \\
\text { A.ml. }\end{array}$ & $\begin{array}{c}182 \cdot 9(80-276) \\
159 \cdot 7(35-294) \\
31 \cdot 5(1-110)\end{array}$ & $\begin{array}{l}0 \cdot 16(0-0 \cdot 7) \\
0 \cdot 15(0-0 \cdot 81) \\
0 \cdot 32(0-1 \cdot 37)\end{array}$ \\
\hline
\end{tabular}

Abbreviations: A.f. =Anopheles funestus; A.g.=Anopheles gambiae; A.a.=Anopheles arabiensis; A.mr. =Anopheles merus; A.ml. = Anopheles melas; $\mathrm{mf}=$ microfilariae.

APPENDIX 2. QUANTIFYING THE UPTAKE CURVE FOR ANOPHELES

\section{Methods}

The uptake curve describes the relationship between mf density in the human blood and the number of L3 larvae developing in mosquitoes after feeding. To quantify this curve for Anopheles, we analyzed data about the average number of L3 larvae developing in a batch of mosquitoes that fed on an infected human with known mf density. Raw data were available from a field study in Ghana (Boakye et al. 2004). The few available data from published feeding experiments were also used (Bryan and Southgate, $1988 a, b$; Southgate and Bryan, 1992). Summary information of the different studies is provided in Table 4.

To enable combined analysis of the data from different studies, we first standardized the $\mathrm{mf}$ counts to the expected count in a $20 \mu \mathrm{L}$ finger prick blood smear. When reported $\mathrm{mf}$ counts were based on $\leqslant 100 \mu \mathrm{L}$ finger prick blood, we only applied a correction for volume. To transform $\mathrm{mf}$ count in $1 \mathrm{~mL}$ venous blood to corresponding count in $20 \mu \mathrm{l}$ finger prick blood, we used the relationship that was derived by Snow and Michael (2002): $y=0 \cdot 037 x+0 \cdot 1449 x^{2}-$ 0.0309 , where: $y=\log _{10}$ (Mf count in $20 \mu \mathrm{L}$ blood +1 ), $x=\log _{10}$ (Mf count in $1 \mathrm{ml}$ blood +1 ).

Subsequently, we quantified the relationship between the standardized $\mathrm{mf}$ count in the human blood (mf per $20 \mu \mathrm{L}$ ) and the mean number of L3 developing in mosquitoes after feeding, by fitting equation 1 to the data.

$L 3=a\left(1-\exp \left(-(b M)^{c}\right)\right.$ with $L 3=$ the average number of L3 larvae developing in mosquitoes; $M=$ the $\mathrm{mf}$ density in human blood as counted in a $20 \mu \mathrm{L}$ night blood smear; $a=$ the maximum number of L3 larvae that can develop in mosquitoes; $b=1 /$ scale; $c=$ powerparameter. Depending on the value of the parameter $c$, this curve takes a saturating $(c<1)$ or sigmoid form $(c>1)$. The latter is suitable for describing 'facilitation' in the mf uptake and development, which is assumed for Anopheles: the number of L3 developing in mosquitoes initially increases more than proportional with the $\mathrm{mf}$ density in the human blood, but at higher densities limiting mechanisms get the upper hand so that saturation occurs (Southgate and Bryan, 1992; Duerr et al. 2005).

Using the non-linear regression procedure (PROC NLIN) in SAS (v8.2), we estimated the values of parameters $a, b$ and $c$ with the least squares method. Observations were weighed for the number of mosquitoes examined. The weights $\left(W_{i}\right)$ were calculated as :

$W_{i}=\sqrt{x_{i}} / \sum_{i}^{n} \sqrt{x_{i}}$

with $x_{i}$ the number of mosquitoes examined for observation $i$, and $n$ the total number of observations included in the analysis. To prevent exclusion of observations with zero $\mathrm{mf}$ counts, we replaced the zeros by half the detection limit (with the detection limit being calculated as $1 /$ (total blood volume examined in $\mu \mathrm{L}) * 20 \mu \mathrm{L}$ ).

Likelihood-based confidence intervals were calculated for parameter $c$ (Kalbfleish, 1979). Confidence boundaries for this parameter were derived 


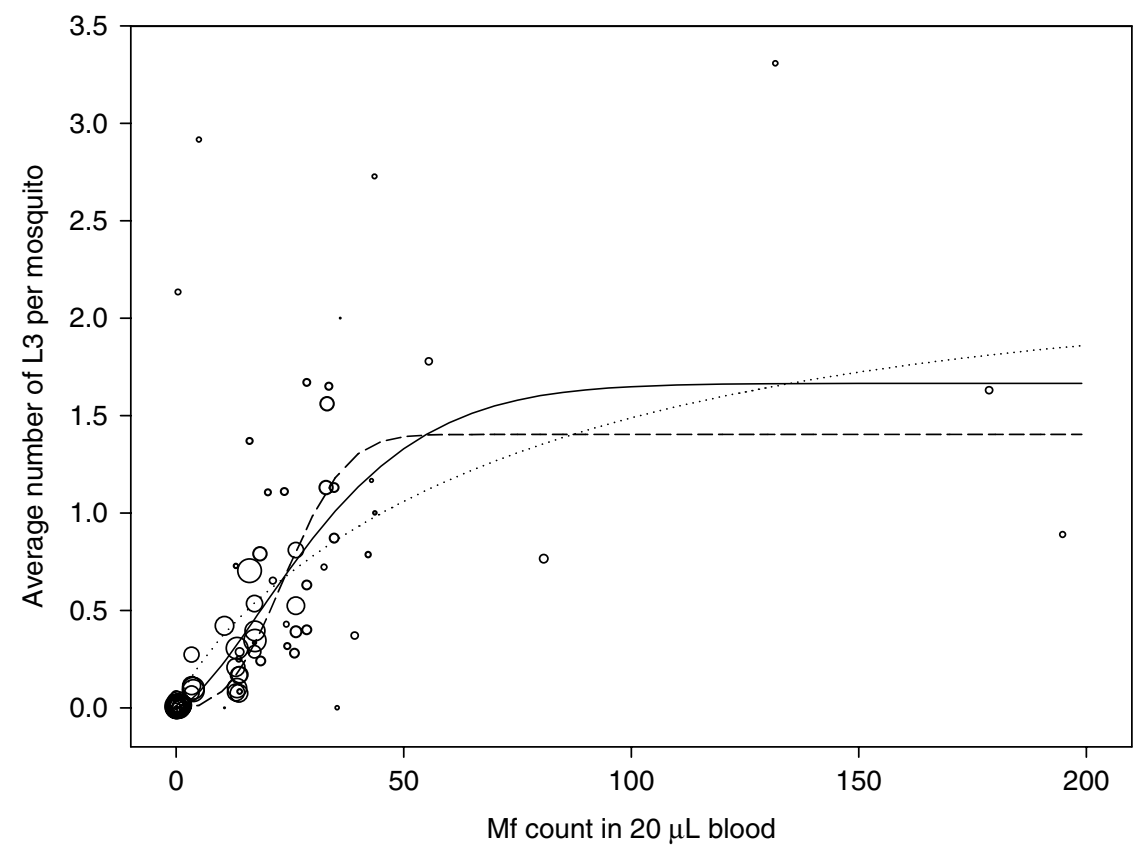

Fig. 6. Uptake curve, showing the relation between the mf count in human blood ( $\mathrm{mf}$ per $20 \mu \mathrm{L}$ of blood) and the average number of L3 developing per mosquito after a blood meal. Observations are shown as open circles and the circle size correlates to the number of mosquitoes examined. The solid line shows the best fitting curve; the dotted and dashed lines respectively give the curves that correspond to the lower and upper boundary for parameter $c$ (the severity of density dependence).

iteratively, by searching for the highest and lowest possible value that did not give a significantly worse fit to the data as assessed via the sum of squared errors (SSE). The maximum acceptable SSE (corresponding to the boundaries of the $95 \%$ confidence interval for parameter $c$ ) is given by $\mathrm{SSE}_{\mathrm{opt}}+3 \cdot 84 *$ scale, with the scale calculated as the sum of squared errors of the optimized model divided by the corresponding degrees of freedom $\left(\mathrm{SSE}_{\mathrm{opt}} / \mathrm{d}\right.$.f.).

\section{Results}

The observations and estimated curves are shown in Fig. 6. There were 81 observations in total. The number of mosquitoes on which observations were based varied widely, from 1 to 294 . Point estimates of the parameters of equation 1 were: $a=1 \cdot 67$, $b=0 \cdot 027$, and $c=1 \cdot 51$. The solid line in Fig. 6 shows the shape of the uptake curve. The value of $c>1$ gives the curve a sigmoid shape, indicating that there is facilitation in the relationship between $\mathrm{mf}$ density in the human blood and the L 3 yield per mf. However, the data used for estimation were highly variable and some uncertainty remains about the strength of density dependence. The dotted and dashed lines correspond to the upper and lower boundaries of the $95 \%$ confidence interval for the parameter $c$, respectively resulting in curves with weaker facilitation $(a=2 \cdot 11, b=0.013, c=0 \cdot 81)$ or stronger facilitation $(a=1 \cdot 40, b=0.036, c=2 \cdot 72)$. Note that the dotted curve in fact shows limitation: the L3 yield per $\mathrm{mf}$ is highest at the lowest $\mathrm{mf}$ density and continuously declines with increasing $\mathrm{mf}$ density. 